\title{
Photodynamic therapy with a novel porphyrin-based photosensitizer against human gastric cancer
}

\author{
JING-JING CHEN ${ }^{1}$, LI-JING GAO ${ }^{2}$ and TIAN-JUN LIU ${ }^{3}$ \\ ${ }^{1}$ Department of Pharmacology of Changzhi Medical College; ${ }^{2}$ Department of Physiology, \\ Changzhi Medical College, Changzhi, Shanxi 046000; ${ }^{3}$ Institute of Biomedical Engineering, \\ Peking Union Medical College and Chinese Academy of Medical Sciences, Tianjin 300192, P.R. China
}

Received November 15, 2014; Accepted October 2, 2015

DOI: $10.3892 / \mathrm{ol} .2015 .3953$

\begin{abstract}
The objective of the present study was to evaluate the effects of novel porphyrin-based photosensitizer meso-5-[Q-diethylene triamine pentaacetic acid- aminophenyl]-10,15,20-triphenyl-porphyrin (DTP)-mediated photodynamic therapy (PDT) on the HGC27 and SNU-1 human gastric cancer cell lines. The absorption spectrum of DTP was analyzed using a microplate spectrophotometer. The HGC27 or SNU-1 cells were incubated with DTP and exposed to illumination by a $650-\mathrm{nm}$ laser. The experiments were divided into four groups: A blank control, cells treated with DTP without light, cells exposed to laser light without DTP and cells treated with a combination of DTP and light together. The phototoxicity of DTP was analyzed by 3-(4,5-dimethyl-2-thiazolyl)-2,5-diphenyl-2H-tetrazolium bromide assay. Cell apoptosis was detected by flow cytometry and Hoechst 33342 staining. In addition, the intracellular distribution of DTP was investigated by laser scanning confocal microscopy. DTP-PDT demonstrated marked phototoxicity towards HGC27- and SNU-1 cells. The rate of cell death increased significantly in a DTP concentration-dependent and light dose-dependent manner, with maximum mortality rates of 74.14 and $67.76 \%$, respectively. There were significant differences between the therapeutic and control groups $(\mathrm{P}<0.01)$. In addition, the growth of cells treated with DTP or laser light alone was not inhibited. Further evaluation revealed that, following DTP-PDT, HGC27 and SNU-1 cells demonstrated notable apoptotic changes, including condensed chromatin, fragmented nuclei and apoptotic bodies, and the percentage of apoptotic cells was significantly higher than that of the control groups $(\mathrm{P}<0.01)$. Furthermore, confocal laser scanning microscopy revealed that DTP localized to the lysosomes but
\end{abstract}

Correspondence to: Professor Tian-Jun Liu, Institute of Biomedical Engineering, Peking Union Medical College and Chinese Academy of Medical Sciences, 236 Baidi Road, Tianjin 300192, P.R. China

E-mail: liutianjuntj@126.com

Key words: gastric cancer, novel porphyrin-based photosensitizer, photodynamic therapy, apoptosis, subcellular localization not mitochondria in the two types of tumor cell. In conclusion, significant phototoxicity and reduced cytotoxicity in dark conditions make the novel photosensitizer DTP a promising potential PDT drug for future use in the treatment of human gastric cancer.

\section{Introduction}

Worldwide, gastric cancer is the fourth most common malignant disease and the second leading cause of cancer-associated mortality (1). According to the statistical data of the World Health Organization (2), there were 989,000 novel cases and 737,000 mortalities of gastric cancer in 2008, of which, the ratio of men to women was 2:1. Surgical excision, chemotherapy and radiotherapy are the basic treatment options for gastric cancer, among which, surgical excision is currently the first choice (3). However, the early diagnosis of gastric cancer is difficult and the majority of cases have progressed to a moderate or advanced stage prior to diagnostic confirmation, therefore, the postoperative 5-year survival rate of gastric cancer remains low at $\sim 20-30 \%$. Furthermore, elderly patients are frequently unable to tolerate surgery $(4,5)$. In recent years, improvements to various resection methods, as well as chemotherapeutic and radiotherapeutic plans has had little effect (3). Surgical excision is incapable of removing all tumor cells, and therefore the risk of postoperative recurrence and metastasis remain (6). Furthermore, the major side effects of chemotherapy and radiotherapy, particularly for elderly patients, which include myelosuppression, immunosuppression and diarrhea, may outweigh the curative effects $(7,8)$. Therefore, an effective therapy technique for the treatment of gastric cancer is urgently required.

Photodynamic therapy (PDT) is a non-invasive treatment method, used for a variety of malignant tumors $(9,10)$. PDT has been known to be effective for the treatment of gastric cancer for a number of years $(11,12)$. PDT typically involves the systemic administration of a photosensitizer (PS), followed by its activation by light at an appropriate wavelength, which results in the generation of reactive oxygen species (ROS) and eventually induces malignant cell death (13). PDT has numerous advantages over typical cancer treatment modalities, including surgery, chemotherapy and radiotherapy (14): i) PDT is relatively non-invasive, simply requiring illumination 
of the tumor site, and therefore inducing minimal injury to the adjacent normal tissues (15); ii) PDT does not induce systemic immunosuppressive effects that may be translated into clinical opportunistic infection (15); iii) PDT is able to be repeated without detrimental consequences to the patient (16); and iv) PDT is simple to conduct, and is particularly suitable for elderly patients who may be unable to endure surgery, chemotherapy or radiotherapy (16). In addition, since the laser light required for PDT may be delivered by an optical fiber, PDT is particularly useful for the treatment of cavity-tumor gastric cancer.

A novel porphyrin-based PS, named meso-5-[0-diethylene triamine pentaacetic acid (DTPA)-aminophenyl]-10,15,20-triphenyl-porphyrin (DTP), was recently developed by the present group (17). This compound is a porphyrin derivative and was designed to be a dissymmetrical DTPA-aminophenyl-based porphyrin. DTP is a chemically pure compound and is synthesized according to the patent specifications. The present study aimed to investigate the effects and mechanism of DTP-mediated PDT against human gastric cancer HGC27 and SNU-1 cells.

\section{Materials and methods}

Preparation ofDTP.The synthetic process of DTP was obtained in detail according to the patent specifications (CN 101805362) (17). Initially, meso-5,10,15,20-tetraphenyl-porphyrin was synthesized in propionic acid solvent (Meryer Chemical Technology Co.,Ltd.,Shanghai,China), using the classical Adlermethod (18). Meso-5,10,15,20-tetraphenyl-porphyrin (0.01 mol) was added and stirred into $20 \mathrm{ml}$ dichloromethane (Aladdin Industrial Inc., Shanghai, China) at $-10^{\circ} \mathrm{C}$ until dissolved. Subsequently, $65 \%$ concentrated nitric acid ( $1 \mathrm{ml}$; Aladdin Industrial Inc.) was added to the solution. The nitrated product was reduced with sodium nitrite (Aladdin Industrial Inc.) in dichloromethane at room temperature, until a reduced mixture was gained. The meso-5-(Q-aminophenyl)-10,15,20-triphenyl-porphyrin was obtained as the main product following separation of the mixture by silica gel chromatography. Next, $0.2 \mathrm{~g}$ meso-5-(@-aminophenyl)-10,15,20-triphenyl-porphyrin, $0.446 \mathrm{~g}$ diethylenetriaminepentaacetic acid dianhydride, $0.046 \mathrm{~g}$ dimethylaminopyridine (Aladdin Industrial Inc.) and $0.040 \mathrm{~g}$ triethylamine were dissolved in $10 \mathrm{ml}$ dimethyl sulfoxide (DMSO; Beijing Solarbio Science \& Technology Co., Ltd., Beijing, China) in a $25 \mathrm{ml}$ flask. Following agitation for $12 \mathrm{~h}$ at room temperature, $5 \mathrm{ml} \mathrm{H}_{2} \mathrm{O}$ was added to the reaction solution and a precipitate was formed. The final DTP product was then obtained by crystallizing the precipitate of the mixed solution of DMSO and $\mathrm{H}_{2} \mathrm{O}$. The chemical structure of DTP is shown in Fig. 1. DTP was dissolved in Roswell Park Memorial Institute (RPMI)-1640 medium and stored at $12.5 \times 10^{3} \mu \mathrm{M}$ at $4^{\circ} \mathrm{C}$, protected from visible light.

Cells and culture conditions. The PDT effect of DTP was studied using the HGC27 and SNU-1 human gastric cancer cell lines, which were purchased from the Type Culture Collection of the Chinese Academy of Sciences (Shanghai, China). The two types of cell were cultured in RPMI-1640 culture medium (Beijing Solarbio Science \& Technology Co., Ltd.) with $10 \%$ Gibco fetal bovine serum (FBS; Thermo Fisher

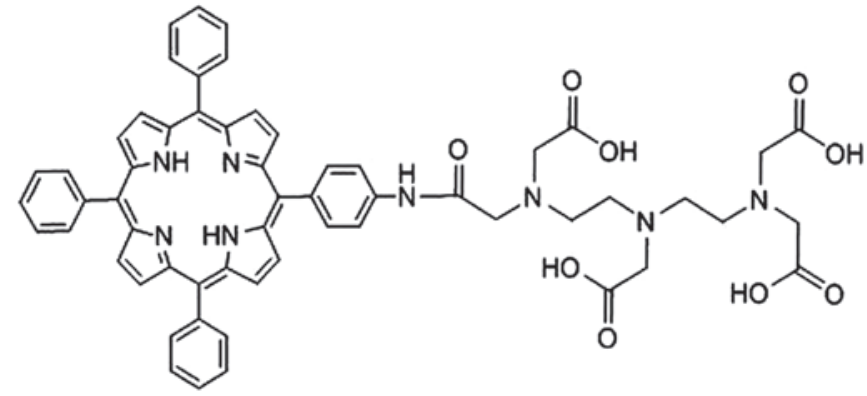

Figure 1. Chemical structure of meso-5-[Q-diethylene triamine pentaacetic acid-aminophenyl]-10,15,20-triphenyl-porphyrin.

Scientific, Waltham, MA, USA) at $37^{\circ} \mathrm{C}$ in a fully humidified atmosphere with $5 \% \mathrm{CO}_{2}$.

Spectral analysis of DTP. DTP solution was prepared in phosphate-buffered saline (PBS; Beijing Solarbio Science \& Technology Co., Ltd.) to produce a solution of $3.12 \mu \mathrm{M}$ concentration. Subsequently, $100 \mu \mathrm{l}$ DTP solution was added into a 96-well plate. The ultraviolet (UV)-visible absorption spectrum was recorded on a microplate spectrophotometer (Thermo 3001; Thermo Fisher Scientific, Waltham, MA, USA).

Photosensitization. HGC27 or SNU-1 cells were loaded into 96-well plates (1×104/well) and incubated in a humidified incubator containing $95 \%$ air and $5 \% \mathrm{CO}_{2}$ until cell attachment to the substratum reached $\sim 80 \%$ confluence. Subsequently, $100 \mu \mathrm{l}$ of various concentrations of DTP were added to the wells and incubated for $24 \mathrm{~h}$. Following incubation, the supernatant was replaced with fresh culture medium supplemented with $10 \%$ FBS and the cells were irradiated with 6 or $12 \mathrm{~J} / \mathrm{cm}^{2}$ of laser light at a wavelength of $650 \mathrm{~nm}$, followed by incubation for an additional $3 \mathrm{~h}$ at $37^{\circ} \mathrm{C}$. The experiment was divided into groups, identical for HGC27 and SNU-1 cells, as follows: Control groups, including untreated cells, cells treated with PS alone and cells exposed to laser light alone; and treatment groups, including cells treated with DTP of various concentrations in combination with laser light energy. The treatment groups comprised: Group $1,0.78 \mu \mathrm{M}$

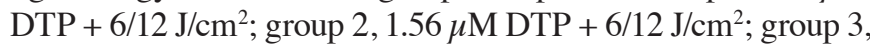
$3.125 \mu \mathrm{M} \mathrm{DTP}+6 / 12 \mathrm{~J} / \mathrm{cm}^{2}$; group 4, $6.25 \mu \mathrm{M} \mathrm{DTP}+6 / 12 \mathrm{~J} / \mathrm{cm}^{2}$ and group $512.5 \mu \mathrm{M} \mathrm{DTP}+6 / 12 \mathrm{~J} / \mathrm{cm}^{2}$.

Colorimetric 3-(4,5-dimethyl-2-thiazolyl)-2, 5-diphenyl-2Htetrazolium bromide (MTT) assay. Cell viability was assessed using the MTT Cell Proliferation and Cytotoxicity Assay Kit' (Amresco, Solon, OH, USA). Following photosensitization, $100 \mu \mathrm{g}$ MTT in $20 \mu \mathrm{l}$ PBS was added into each well (96-well plates) and the cells $\left(1 \times 10^{4} /\right.$ well $)$ were then incubated for a further $3 \mathrm{~h}$. The reaction was stopped by the addition of $180 \mu \mathrm{l}$ DMSO. The optical density (OD) of each sample was subsequently measured at a wavelength of $490 \mathrm{~nm}$ using a microplate spectrophotometer (Thermo 3001; Thermo Fisher Scientific). Cell survival rate $(\%)=\left(\mathrm{OD}_{\text {treated }} / \mathrm{OD}_{\text {control }}\right) \times 100 \%$.

Cell apoptosis. Annexin V-fluorescein isothiocyanate (FITC) and propidium iodide (PI) (Beyotime Institute of Biotechnology, Haimen, China) were used to detect cell apoptosis induced by DTP-PDT. HGC27 and SNU-1 cells were seeded 
in 6-well plates, followed by incubation with $6.25 \mu \mathrm{M}$ DTP for $24 \mathrm{~h}$. The cells were subsequently irradiated at $650 \mathrm{~nm}$ with $12 \mathrm{~J} / \mathrm{cm}^{2}$ laser light. Three hours later, the irradiated cells were collected, rinsed with PBS and stained with Annexin V-FITC (200 $\mu \mathrm{g} / \mathrm{ml}$ ) for $10 \mathrm{~min}$ and $30 \mu \mathrm{g} / \mathrm{ml} \mathrm{PI}$ in the dark at room temperature, successively. Immediately, the fluorescence was analyzed in 10,000 cells/sample using a FACScan flow cytometer (FCM; Beckman Coulter, Fullerton, CA, USA). The results were expressed as the percentage of cells exhibiting apoptosis relative to the total number of cells analyzed. Blank control and treatment with DTP or $6 \mathrm{~J} / \mathrm{cm}^{2}$ laser light alone were included as control groups.

Morphological observations. HGC27 and SNU-1 cells were seeded in 24-well plates. Following attachment to the substratum to $\sim 80 \%$ confluence, $6.25 \mu \mathrm{M}$ DTP was added into each well for $24 \mathrm{~h}$, followed by irradiation by a laser at $650 \mathrm{~nm}$ with $12 \mathrm{~J} / \mathrm{cm}^{2}$. The cells were subsequently stained with Hoechst 33342 (Beijing Solarbio Science \& Technology Co., Ltd.) for $30 \mathrm{~min}$ at room temperature, washed twice with PBS and exposed to UV illumination using a fluorescent microscope (Leica DMIRE 2; Leica Microsystems GmbH, Wetzlar, Germany) to detect the differences in chromatin condensation and fragmentation between the control and treatment groups. The staining was evaluated by three investigators.

Intracellular distribution of PS by confocal laser scanning microscopy (CLSM). HGC27 or SNU-1 cells were cultured on coverslips (Citoglas; Citotest Labware Manufacturing Co., Ltd., Jiangsu, China) placed in Petri dishes (Citoglas; Citotest Labware Manufacturing Co., Ltd.) with RPMI-1640 culture medium. Once the cells reached $85 \%$ confluence, $6.25 \mu \mathrm{M}$ DTP in serum-free cell culture medium was added to the dishes and cells were incubated for $6 \mathrm{~h}$, followed by incubation with: i) $150 \mathrm{nM}$ MitoTracker Green FM for an additional 30 min or ii) $1.5 \mu \mathrm{M}$ LysoSensor ${ }^{\mathrm{TM}}$ Green DND-189 (Invitrogen; Thermo Fisher Scientific, Waltham, MA, USA) for $1 \mathrm{~h}$ at culture temperature. Following incubation, the staining solution was replaced with fresh culture media and the cells were observed by CLSM (TCS SP8; Leica Heidelberg GmbH, Heidelberg, Germany). The excitation wavelength used for DTP was $405 \mathrm{~nm}$, and the fluorescence excitation and emission wavelengths for MitoTracker Green FM or LysoSensor Green DND-189 were 488 and 520 nm, respectively.

Statistical analysis. Statistical analysis was performed based on one way analysis of variance. All statistical analyses were performed using SPSS 11.0 software (SPSS, Inc., Chicago, IL, USA). The results were recorded as the mean \pm standard error of the mean. $\mathrm{P}<0.05$ was considered to indicate a statistically significant difference and all experiments were conducted at least 3 times.

\section{Results}

Spectral analysis of DTP. Initially, a spectral analysis of DTP was conducted (Fig. 2). The absorption spectrum indicated that DTP had significant absorption peaks at wavelengths of 432, $522,560,596$ and $652 \mathrm{~nm}$, respectively. Since the absorption was strongest at $432 \mathrm{~nm}$, absorption at $405 \mathrm{~nm}$ was evaluated, as this

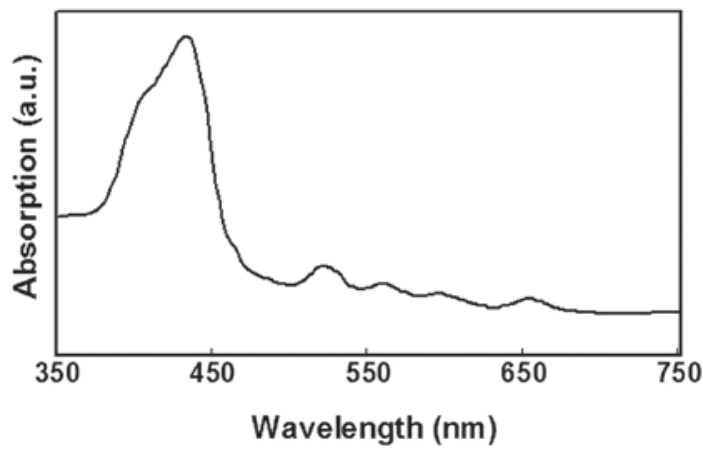

Figure 2. Absorption spectrum of meso-5-[Q-diethylene triamine pentaacetic acid-aminophenyl]-10,15,20-triphenyl-porphyrin.

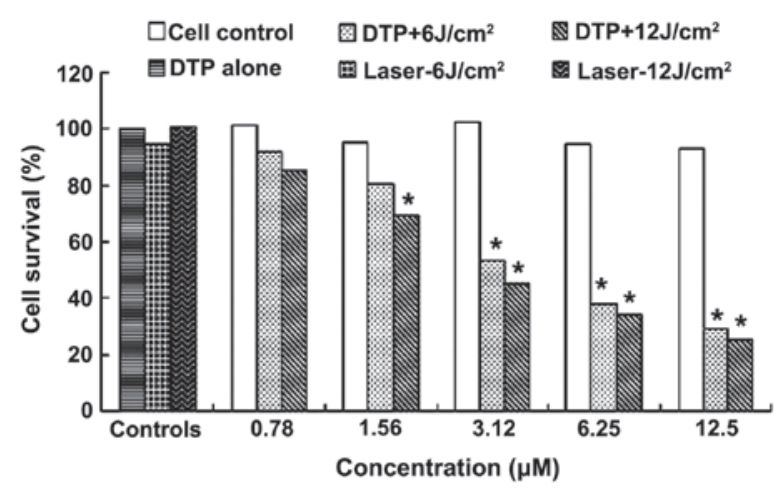

Figure 3. Phototoxicity of DTP against HGC27 cells. DTP meso-5-[Q-diethylene triamine pentaacetic acid-aminophenyl]-10,15,20-triphenyl-porphyrin. ${ }^{*} \mathrm{P}<0.01$ vs. control cells.

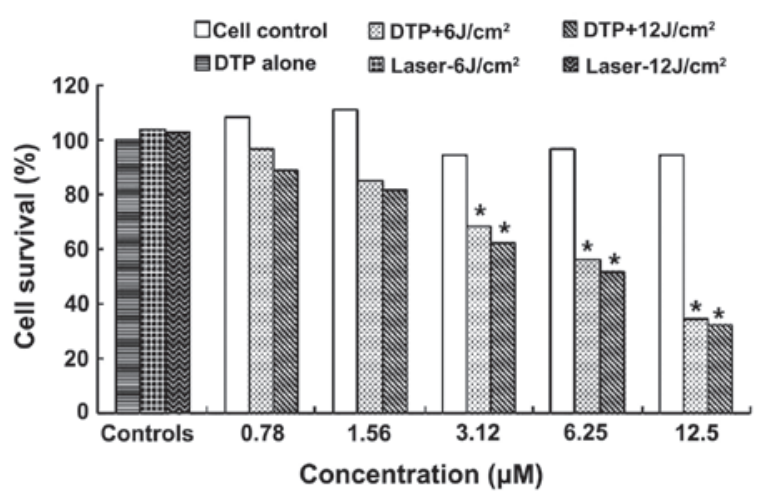

Figure 4. Phototoxicity of DTP against SNU-1 cells. DTP, meso-5-[Q-diethylene triamine pentaacetic acid-aminophenyl]-10,15,20-triphenyl-porphyrin. ${ }^{\mathrm{P}}<0.01$ vs. control cells.

was the closest wavelength which was able to be selected as the excitation laser channel during CLSM analysis. Furthermore, considering the penetration depth of light in PDT proportional to the wavelength, a long wavelength proximal to the red region of the spectrum should be used for laser illumination during treatment with PDT, and $650 \mathrm{~nm}$ is a suitable wavelength for the MTT and flow cytometry assays (19).

DTP combined with laser light induces gastric cancer cell death. The photodynamic effect of DTP against human HGC27 and SNU-1 cells was evaluated by MTT assay. Table IA and B 
Table I. OD values of each group following treatment with DTP alone or in combination with laser light.

A, HGC27 cells

\begin{tabular}{lllll}
\hline & & & \multicolumn{2}{c}{ DTP + laser light, OD } \\
\cline { 3 - 5 } Group & DTP concentration, $\mu \mathrm{M}$ & DTP alone, OD & $6 \mathrm{~J} / \mathrm{cm}^{2}$ & $12 \mathrm{~J} / \mathrm{cm}^{2}$ \\
\hline 1 & 0.78 & $0.8741 \pm 0.1365^{\mathrm{a}}$ & $0.7946 \pm 0.0895^{\mathrm{a}}$ & $0.7368 \pm 0.1305^{\mathrm{a}}$ \\
2 & 1.56 & $0.8249 \pm 0.0549^{\mathrm{a}}$ & $0.6912 \pm 0.6521^{\mathrm{a}}$ & $0.5962 \pm 0.0895^{\mathrm{b}}$ \\
3 & 3.125 & $0.8846 \pm 0.0745^{\mathrm{a}}$ & $0.4595 \pm 0.0352^{\mathrm{b}}$ & $0.3892 \pm 0.0421^{\mathrm{b}}$ \\
4 & 6.25 & $0.8186 \pm 0.1026^{\mathrm{a}}$ & $0.3265 \pm 0.0451^{\mathrm{b}}$ & $0.2956 \pm 0.0512^{\mathrm{b}}$ \\
5 & 12.5 & $0.8018 \pm 0.0982^{\mathrm{a}}$ & $0.2498 \pm 0.0213^{\mathrm{b}}$ & $0.2228 \pm 0.0231^{\mathrm{b}}$ \\
6 & 0.0 & & $0.8165 \pm 0.0951^{\mathrm{a}}$ & $0.8694 \pm 0.1543^{\mathrm{a}}$ \\
7 & Control & & $0.8741 \pm 0.1116$ & \\
\hline
\end{tabular}

B, SNU-1 cells

\begin{tabular}{|c|c|c|c|c|}
\hline \multirow[b]{2}{*}{ Group } & \multirow[b]{2}{*}{ DTP concentration, $\mu \mathrm{M}$} & \multirow[b]{2}{*}{ DTP alone, OD } & \multicolumn{2}{|c|}{ DTP + laser light, OD } \\
\hline & & & $6 \mathrm{~J} / \mathrm{cm}^{2}$ & $12 \mathrm{~J} / \mathrm{cm}^{2}$ \\
\hline 1 & 0.78 & $0.8315 \pm 0.0865^{\mathrm{a}}$ & $0.7425 \pm 0.0745^{\mathrm{a}}$ & $0.6815 \pm 0.0351^{\mathrm{a}}$ \\
\hline 2 & 1.56 & $0.8513 \pm 0.1065^{\mathrm{a}}$ & $0.6522 \pm 0.0534^{\mathrm{a}}$ & $0.6258 \pm 0.0541^{\mathrm{a}}$ \\
\hline 3 & 3.125 & $0.7231 \pm 0.0256^{\mathrm{a}}$ & $0.5236 \pm 0.0982^{\mathrm{b}}$ & $0.4788 \pm 0.0255^{\mathrm{b}}$ \\
\hline 4 & 6.25 & $0.7452 \pm 0.5614^{\mathrm{a}}$ & $0.4322 \pm 0.0415^{\mathrm{b}}$ & $0.3975 \pm 0.0413^{\mathrm{b}}$ \\
\hline 5 & 12.5 & $0.7259 \pm 0.0635^{\mathrm{a}}$ & $0.2655 \pm 0.0265^{\mathrm{b}}$ & $0.2469 \pm 0.0215^{b}$ \\
\hline 6 & 0.0 & & $0.7985 \pm 0.0261^{\mathrm{a}}$ & $0.7865 \pm 0.0452^{\mathrm{a}}$ \\
\hline 7 & Control & & $0.7656 \pm 0.0915$ & \\
\hline
\end{tabular}

${ }^{a} \mathrm{P}>0.05$ vs. control; ${ }^{b} \mathrm{P}<0.01$ vs. control. OD, optical density; DTP, meso-5-[Q-diethylene triamine pentaacetic acid-aminophenyl]-10,15,20triphenyl-porphyrin.

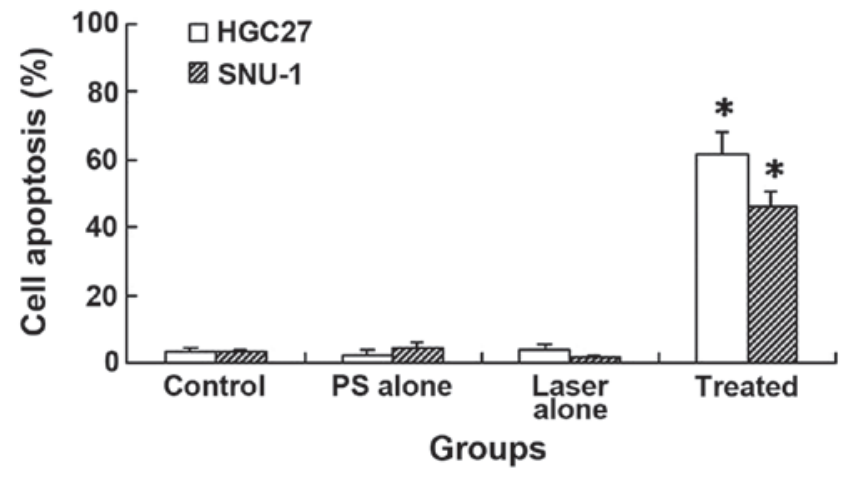

Figure 5. Cell apoptosis following meso-5-[Q-diethylene triamine pentaacetic acid-aminophenyl]-10,15,20-triphenyl-porphyrin photodynamic therapy. ${ }^{*} \mathrm{P}<0.01$ vs. control.

list the OD values of each group and Figs. 3 and 4 demonstrate the corresponding cell survival rates following PDT for HGC27 and SNU-1 cells, respectively.

Table IA and Fig. 3 exhibit the MTT assay results for DTP-PDT on HGC27 cells. The cell survival rate following DTP-PDT declined with increasing PS concentration and light dose (Fig. 3). Statistically significant differences were observed between treatment groups 3-5 and the cell control group $(\mathrm{P}<0.01)$ following exposure to $6 \mathrm{~J} / \mathrm{cm}^{2}$ illumination, while following $12 \mathrm{~J} / \mathrm{cm}^{2}$ treatment, a significant difference was identified between treatment groups 2-5 and the cell control group $(\mathrm{P}<0.01)$ (Table IA). Fig. 3 also demonstrated that $0.78 \mu \mathrm{M}$ PS-mediated PDT only induced slight HGC27 cell death, with $\sim 7.75$ and $14.46 \%$ cell death at 6 and $12 \mathrm{~J} / \mathrm{cm}^{2}$ illumination, respectively. However, treatment with $3.12 \mu \mathrm{M}$ PS was able to induce 46.65 and $54.82 \%$ cell death. The highest concentration of DTP $(12.5 \mu \mathrm{M})$ was found to be highly effective, inducing 70.99 and $74.14 \%$ mortality at light doses of 6 and $12 \mathrm{~J} / \mathrm{cm}^{2}$, respectively. The $\mathrm{IC}_{50}$ of DTP was 4.75 and $2.98 \mu \mathrm{M}$ at light doses of 6 and $12 \mathrm{~J} / \mathrm{cm}^{2}$, respectively. DTP alone exerted no marked cytotoxicity on HGC27 cells at any concentration. In addition, laser light alone also did not exert any effects on the growth of HGC27 cells.

SNU-1 cells demonstrated similar MTT results to those observed in HGC27 cells (Table IB; Fig. 4). DTP exerted significant apoptosis induction in SNU-1 cells. A significant difference was observed between treatment groups 3-5 and the cell control group $(\mathrm{P}<0.01)$ for light doses of 6 and $12 \mathrm{~J} / \mathrm{cm}^{2}$, while no difference was detected between treatment groups 1 and 2 and the cell control $(\mathrm{P}>0.05)$ (Table IB). The death of SNU-1 cells induced by DTP-PDT was proportional to PS concentration and light dose (Fig. 4). The lower concentrations of 0.78 and $1.56 \mu \mathrm{M}$ resulted in the death of a small percentage cells at light doses of 6 and $12 \mathrm{~J} / \mathrm{cm}^{2}$, respectively; however, 


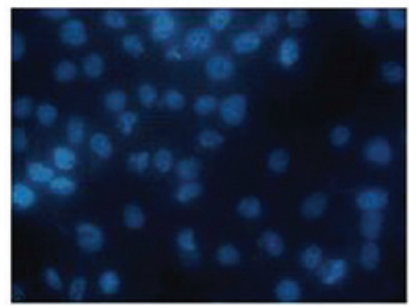

Cell control (HGC27)

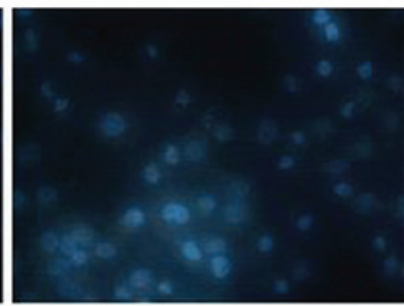

DTP alone (HGC27)

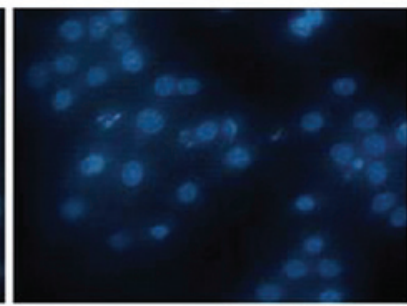

Laser alone (HGC27)

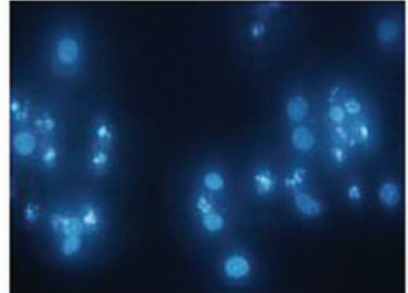

DTP+Laser (HGC27)

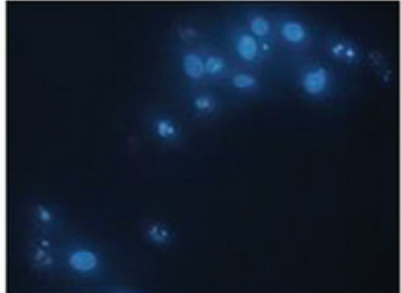

DTP+Laser (SNU-1)

Figure 6. Morphological changes in the cells of each group. DTP, meso-5-[@-diethylene triamine pentaacetic acid-aminophenyl]-10,15,20-triphenyl-porphyrin.

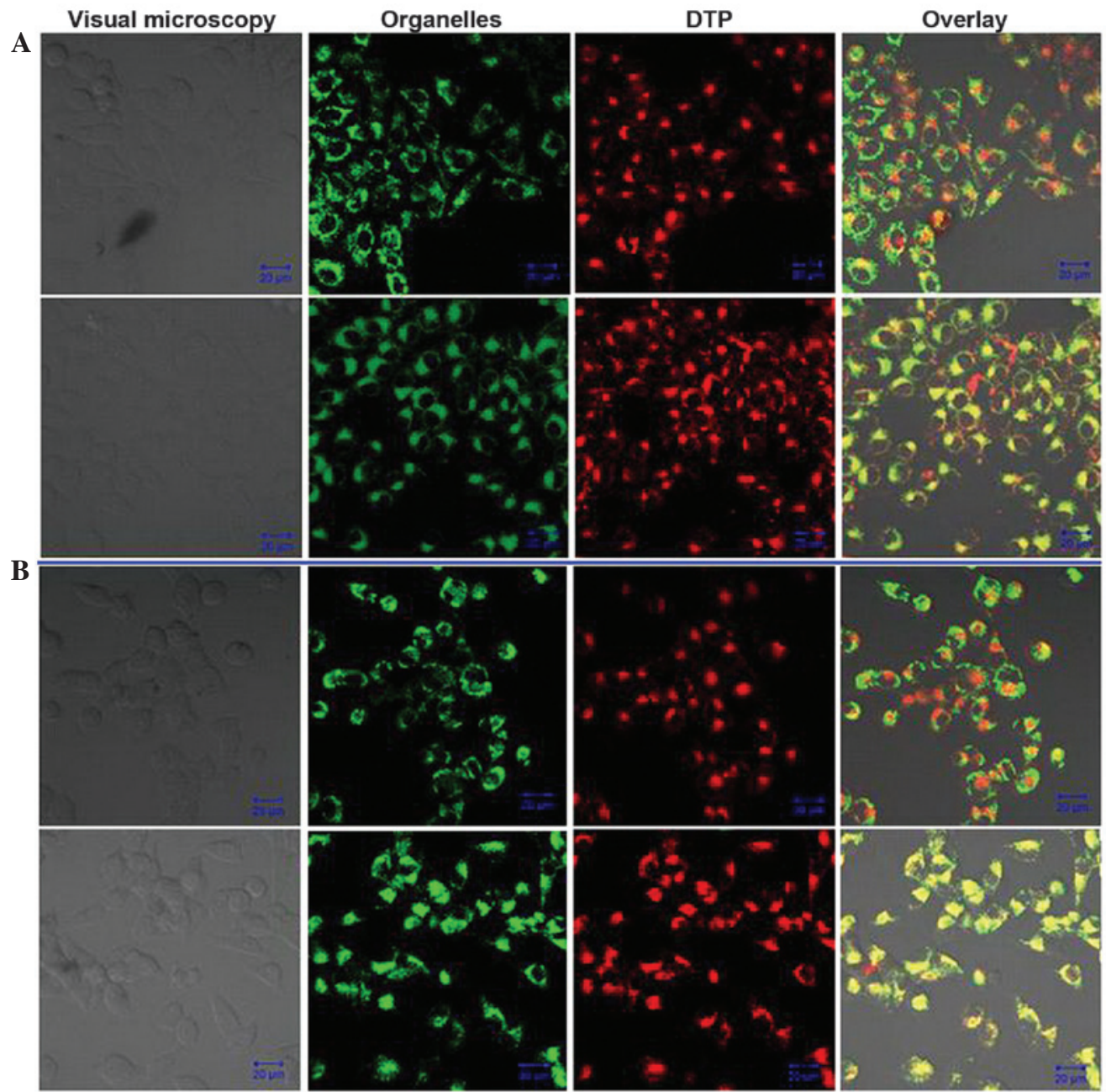

Figure 7. Intracellular distribution of DTP in (A) HGC27 and (B) SNU-1 cells (upper panels, mitochondria; lower panels, lysosomes). Green fluorescence is from the mitochondrial probe and red fluorescence is from the lysosomal probe. The overlay shows the green and red fluorescence together. Scale bar, $20 \mu \mathrm{m}$. DTP, meso-5-[@-diethylene triamine pentaacetic acid-aminophenyl]-10,15,20-triphenyl-porphyrin.

$12.5 \mu \mathrm{M}$ DTP induced 65.33 and $67.76 \%$ mortality and an $\mathrm{IC}_{50}$ of 4.75 and $6.38 \mu \mathrm{M}$, respectively. The data also revealed that DTP or laser treatment alone were nontoxic to SNU-1 cells.
DTP-PDT induces gastric cancer cell apoptosis. DTP-PDT induced significant cell apoptosis in HGC27 and SNU-1 cells, as determined by FCM analysis (Fig. 5). The apoptotic rates 
of HGC27 and SNU-1 cells were $61.5 \pm 6.56$ and $45.9 \pm 4.62 \%$, respectively. These values were significantly higher than those of the control groups $(\mathrm{P}<0.01)$, which demonstrated $3.1 \pm 1.25$ and $2.9 \pm 0.85 \%$ apoptosis in $\mathrm{HGC} 27$ and SNU-1 cells, respectively. In the DTP alone group, only $2.5 \pm 0.98$ and $4.3 \pm 1.25 \%$ cell apoptosis was detected, while $3.7 \pm 1.64$ and $1.8 \pm 0.75 \%$ cell apoptosis were detected in the laser light alone group for HGC27 and SNU-1 cells, respectively. Therefore, no significant differences were detected, in comparison with the cell control $(\mathrm{P}>0.05)$.

Morphological changes occur in gastric cancer cells following PDT. Morphological changes in the cellular nuclei of each group were observed using fluorescence microscopy (Fig. 6). A large quantity of apoptotic cells were detected following PS-PDT, demonstrating significant characteristics of apoptosis, including chromatin condensation, nucleus fragmentation and apoptotic bodies in HGC27 and SNU-1 cells. By contrast, in the control cell, DTP-alone or light-alone groups, the majority of the cells demonstrated intact, rounded/elliptical nuclei and demonstrated no morphological changes in either of the cell types.

DTP is localized to the lysosomes. The distribution of DTP within HGC27 and SNU-1 cells was evaluated via fluorescent observation by CLSM (Fig. 7). Following the incubation of cells with DTP and MitoTracker Green Probe or LysoSensor Green Probe, the PS emitted red fluorescence that was excited by the $405 \mathrm{~nm}$ wavelength and the MitoTracker Green Probe and LysoSensor Green Probe emitted green fluorescence that was excited by the $488 \mathrm{~nm}$ wavelength in the same view. The lysosomal overlay images for $\mathrm{HGC} 27$ and SNU-1 cells revealed a large quantity of yellow-green fluorescent spots (Fig. 7, lower panels), indicating co-localization of DTP and the lysosomal probe. Conversely, no overlap was detectable between DTP and the mitochondrial probe for the two types of cell (Fig. 7, upper panels). The distribution of DTP in HGC27 and SNU-1 cells was analogous.

\section{Discussion}

PDT is a novel treatment for malignant tumors, which is derived from 'photodynamic action' (20). In 1900, Raab (21) discovered that paramecium, having absorbed acridines, were able to be killed by light illumination; however, light or acridines alone did not produce this effect. This phenomenon was subsequently known as 'photodynamic action'. In 1960, Lipson et al (22) prepared the PS, hematoporphyrin derivative and evaluated its effects in the treatment of malignant tumors. Kato et al (23), in 1980, successfully introduced the application of an endoscope to deliver laser light during PDT treatment of lung cancer, which initiated the application of PDT in the therapy of cavity tumors. To date, numerous studies and practices have been focused on the PDT treatment of gastric cancer and have proven that this method is an effective technology for use in the treatment of gastric cancer $(11,24)$.

PDT consists of a PS, laser light and oxygen, among which, PS is the most important component. The four main classes of PS are: Porphyrin derivatives, chlorins, phthalocyanines and porphycenes. These each possess distinct photochemical and photophysical properties, underlying their mechanisms of action and light activation (25). DTP, evaluated in the present study, belongs to the porphyrin derivatives family. The advantages of DTP when compared with other porphyrin derivatives were as follows: i) DTP is a pure compound with clear chemical and optical properties, and was able to be synthesized relatively easily, according to the patent specifications; ii) DTP exhibited improved chemical and physical stability; iii) DTP demonstrated little toxicity in dark conditions and is relatively safe for PDT treatment; iv) DTP has an absorption peak of $652 \mathrm{~nm}$, which is optimal for PDT use; and v) the authors of the present study have applied for patent protection of the compound. These advantages make the novel photosensitizer DTP a promising potential PDT drug for use in the treatment of gastric cancer, and therefore prompted initiation of the present study.

Initially, the photodynamic effects of DTP on $\mathrm{HGC} 27$ and SNU-1 human gastric cancer cells were evaluated by MTT assay. The results revealed that DTP exerted marked phototoxicity on the two types of cell. In HGC27 cells, a concentration of $6.25 \mu \mathrm{M}$ DTP-PDT resulted in 62.09 and $65.68 \%$ cell death at light doses of 6 and $12 \mathrm{~J} / \mathrm{cm}^{2}$, respectively. Furthermore, treatment with $12.5 \mu \mathrm{M}$ induced 70.99 and $74.14 \%$ mortality, respectively. Similar phototoxicity was observed in SNU-1 cells. A concentration of $12.5 \mu \mathrm{M}$ DTP-PDT induced 65.33 and $67.74 \%$ cell death at light doses of 6 and $12 \mathrm{~J} / \mathrm{cm}^{2}$, respectively, and the corresponding $\mathrm{IC}_{50}$ was 4.75 and $6.38 \mu \mathrm{M}$, respectively. However, in the absence of light stimulation, DTP did not exert any significant damage on the cells, even at the highest concentration of $12.5 \mu \mathrm{M}$. These data indicate that this PS is a safe and effective PDT drug for the treatment of gastric cancer cells, and the therapeutic effects were associated with PS concentration and light dose.

To further investigate the mechanism of DTP-mediated PDT on HGC27 and SNU-1 cells, flow cytometry and Hoechst 33342 staining were used to analyze cell apoptosis. Flow cytometric analysis revealed that DTP-PDT was able to induce marked apoptosis of HGC27 and SNU-1 cells, and that the apoptotic rate was $61.5 \pm 6.56$ and $45.9 \pm 4.62 \%$, respectively, significantly higher than that of the control group. Additionally, fluorescent microscope observation following Hoechst 33342 staining identified a large number of apoptotic cells in the DTP-PDT treatment group. By contrast, the majority of cells in the control groups remained rounded and intact. The above results supported the hypothesis that apoptosis is involved in the death process triggered by DTP-PDT in HGC27 and SNU-1 cells.

The intracellular localization of a PS is crucial for photodynamic damage. It is the ROS generated by PS that induce cell death during PDT. Since ROS have a short half-life and are only able to act close to the site of generation (26), photodynamic damage is closely associated with the generation of ROS within cells, and therefore to the precise intracellular localization of PS. PSs are able to localize various organelles within cells, including the mitochondria, lysosomes, endoplasmic reticulum, Golgi apparatus and plasma membranes (27). Generally, PS distribution in mitochondria commonly activates cell apoptosis through various pathways, while PS distribution in lysosomes frequently leads to cell necrosis (28). The present study showed that DTP localized within the lysosomes of HGC27 and SNU-1 cells, but induced apoptosis as the major death mode. This phenomenon may be due to the indirect mitochondrial injury induced by direct 
lysosome damage by DTP-PDT. It has been reported that the permeability of the mitochondrial membrane was increased by PDT-mediated lysosomal damage, which indirectly results in apoptosis of tumor cells (29). Photodynamically-produced ROS by lysosomal PS, induced rapid destruction of lysosomes, resulting in the release of cathepsins, inducing the following spatiotemporal sequence of cellular events: Bid/Bax activation, cytochrome $c$ release from the mitochondria to cytosol, activation of downstream caspases and subsequent apoptisis $(30,31)$. Nagata et al (32) revealed that the PS ATX-S10 (Na) had a primary site of accumulation in lysosomes, however cells underwent apoptosis following illumination, leading to $70 \%$ cell death. The results of these studies were in agreement with those of the present study.

In conclusion, the results of the present study indicate that the novel porphyrin-based PS, DTP, exhibited significant PDT effects on HGC27 and SNU-1 human gastric cancer cells in vitro, and that DTP is safe for use in the PDT process. This compound localized in the lysosomes of HGC27 and SNU-1 cells, but indirectly induced the mitochondrial apoptotic pathway. Further investigations, including animal experiments and additional molecular mechanism of action investigations should be conducted for this compound in order to verify its potential clinical application for the treatment of human gastric cancer.

\section{References}

1. Wong JE, Ito Y, Correa P, Peeters KC, van de Velde CJ, Sasako M and Macdonald J: Therapeutic strategies in gastric cancer. J Clin Oncol 21 (23 Suppl): 267s-269s, 2003 .

2. Ferlay J, Shin HR, Bray F, Forman D, Mathers C and Parkin DM: Estimates of worldwide burden of cancer in 2008: GLOBOCAN 2008. Int J Cancer 127: 2893-2917, 2010.

3. Gu JR and Cao XT: Conceptual consideration of cancer, challenges and opportunities for cancer biotherapy. Zhong Guo Zhong Liu Sheng Wu Zhi Liao Za Zhi Bian Ji Bu 15: 2-7, 2008 (In Chinese).

4. Liu X, Ru J, Zhang J, Zhu LH, Liu M, Li X and Tang H: miR-23a targets interferon regulatory factor 1 and modulates cellular proliferation and paclitaxel-induced apoptosis in gastric adenocarcinoma cells. PLoS One 8: e64707, 2013.

5. Li H, Liu Z, Xu C, Chen Y, Zhang J, Cui B, Chen X, An G, She X, Liu H, et al: Overexpression of S100A4 is closely associated with the progression and prognosis of gastric cancer in young patients. Oncol Lett 5: 1485-1490, 2013.

6. Zhang ZQ, Yao HL, Wen Y, Miao XY and Xiong L: Advances in photodynamic therapy for gastric cancer. Ji Guang Sheng Wu Xue Bao Bian Ji Bu 21: 289-293, 2012 (In Chinese).

7. Pan XR and Chen XX: Recent development on adverse reactions induced by cancer chemotherapy treated with traditional Chinese medicine. Yi Yao Yu Bao Jian Bian Ji Bu 16: 2358-2360, 2010 (In Chinese)

8. Ma XQ, He TQ, Zheng Tao, Xu BX, Xiao CR, Zheng SX, Lin XR, Gao PY, Shen G, Bao YH, et al: Clinical study on protective effect of diltiazem against radiation injuries on cancer. Zhong Guo Yao Xue Za Zhi Bian Ji Bu 39: 231-232, 2004 (In Chinese).

9. Vrouenraets MB, Visser GWM, Snow GB and van Dongen GA: Basic principles, applications in oncology and improved selectivity of photodynamic therapy. Anticancer Res 23: 505-522, 2003.

10. Nowak-Stepniowska A, Pergoł P and Padzik-Graczyk A: Photodynamic method of cancer diagnosis and therapy - mechanisms and applications. Postepy Biochem 59: 53-63, 2013 (In Polish).

11. Karanov SI: Long-term results after photodynamic therapy (PDT) of T1N0M0 gastrointestinal (GI) tumors. Hepatogastroenterology 49: 1579-1581, 2002.
12. Ell C, Gossner L, May A, Schneider HT, Hahn EG, Stolte $M$ and Sroka R: Photodynamic ablation of early cancers of the stomach by means of mTHPC and laser irradiation: Preliminary clinical experience. Gut 43: 345-349, 1998.

13. Grimm S, Mvondo D, Grune T and Breusing N: The outcome of 5-ALA-mediated photodynamic treatment in melanoma cells is influenced by vitamin $\mathrm{C}$ and heme oxygenase- 1 . Biofactors 37: 17-24, 2011.

14. Sibata CH, Colussi VC, Oleinick NL and Kinsella TJ: Photodynamic therapy in oncology. Expert Opin Pharmacother 2: 917-927, 2001.

15. Selbo PK, Høgset A, Prasmickaite L and Berg K: Photochemical internalisation: A novel drug delivery system. Tumour Biol 23: 103-112, 2002

16. Rockson SG, Lorenz DP, Cheong WF and Woodburn KW: Photoangioplasty. An emerging clinical cardiovascular role for photodynamic therapy. Circulation 102: 591-596, 2000.

17. Liu TJ, Wang YM, Wu L and Lv F: [Diethylenetriaminepentaac etaacetato-N,N',N"]gadolinium-modified porphyrins, and preparation method and application thereof. 0086; CN 101805362. Filed March 30, 2010; issued August 18, 2010.

18. Adler AD, Longo FR, Finarelli JD, Goldmacher J, Assour J and Korsakoff L: A simplified synthesis for meso-tetraphenylporphine. J Org Chem 32: 467-477, 1967.

19. Yan YJ, Zheng MZ, Chen ZL, Yu XH, Yang XX, Ding ZL and $\mathrm{Xu}$ L: Studies on preparation and photodynamic mechanism of chlorin P6-13,15-N-(cyclohexyl)cycloimide (Chlorin-H) and its antitumor effect for photodynamic therapy in vitro and in vivo. Bioorg Med Chem 18: 6282-6291, 2010.

20. Juarranz A, Jaén P, Sanz-Rodríguez F, Cuevas J and González S: Photodynamic therapy of cancer. Basic principles and applications. Clin Transl Oncol 10: 148-154, 2008.

21. Raab O: The effect of fluorescent substances on infusoria. Z Biol 39: 524-526, 1900

22. Lipson RL, Baldes EJ and Olsen AM: Hematoporphyrin derivative: A new aid for endoscopic detection of malignant disease. J Thorac Cardiovasc Surg 42: 623-629, 1961.

23. Kato H, Konaka C, Saito M, Nishimiya K, Kawate N, Aizawa K and Hayata Y: Laser photodynamic therapy with hematoporphyrin derivative in lung cancer. Nihon Geka Gakkai Zasshi 86: 1059-1063, 1985 (In Japanese).

24. Nakamura H, Yanai H, Nishikawa J, Okamoto T, Hirano A, Higaki M, Omori K, Yoshida T and Okita K: Experience with photodynamic therapy (endoscopic laser therapy) for the treatment of early gastric cancer. Hepatogastroenterology 48: 1599-1603, 2001

25. De Rosa FS and Bentley MVLB: Photodynamic therapy of skin cancers: Sensitizers, clinical studies and future directives. Pharm Res 17: 1447-1455, 2000.

26. Waidelich R: Laser-induced lithotripsy and photodynamic therapy in urology - A short introduction to current laser applications. Med Laser Appl 25: 14-19, 2010.

27. Pazos M and Nader HB: Effect of photodynamic therapy on the extracellular matrix and associated components. Braz J Med Biol Res 40: 1025-1035, 2007.

28. Ali SM and Olivo M: Bio-distribution and subcellular localization of Hypericin and its role in PDT induced apoptosis in cancer cells. Int J Oncol 21: 531-540, 2002.

29. Garg AD, Nowis D, Golab J and Agostinis P: Photodynamic therapy: Illuminating the road from cell death towards anti-tumour immunity. Apoptosis 15: 1050-1071, 2010.

30. Liu L, Zhang Z and Xing D: Cell death via mitochondrial apoptotic pathway due to activation of Bax by lysosomal photodamage. Free Radic Biol Med 51: 53-68, 2011.

31. Chiu SM, Xue LY, Lam M, Rodriguez ME, Zhang P, Kenney ME, Nieminen AL and Oleinick NL: A requirement for bid for induction of apoptosis by photodynamic therapy with a lysosome- but not a mitochondrion-targeted photosensitizer. Photochem Photobiol 86: 1161-1173, 2010.

32. Nagata S, Obana A, Gohto $Y$ and Nakajima S: Necrotic and apoptotic cell death of human malignant melanoma cells following photodynamic therapy using an amphiphilic photosensitizer, ATX-S10(Na). Lasers Surg Med 33: 64-70, 2003. 